\title{
Just the facts: evaluation and management of thermal burns
}

\author{
Brit Long ${ }^{1}$ (1) $\cdot$ John Christopher Graybill ${ }^{2} \cdot$ Hans Rosenberg ${ }^{3}$
}

Received: 30 May 2021 / Accepted: 4 October 2021 / Published online: 2 November 2021

This is a U.S. government work and not under copyright protection in the U.S.; foreign copyright protection may apply 2021

Keywords Burns · Thermal injury $\cdot$ Inhalation injury

\section{Clinical scenario}

A 42-year-old male presents with burns to the chest, abdomen/pelvis, and upper extremities after pouring accelerant on a fire outside. Vital signs include heart rate 132 beats per minute, blood pressure 155/92 $\mathrm{mm} \mathrm{Hg}$, and saturation $97 \%$ on room air. He denies traumatic injury. His face and oropharynx display no evidence of soot, and there is no hoarse voice or upper airway edema. He has both wet and dry blisters, with variable blanching and areas ranging from insensate to severe pain.

\section{What are important components of the initial evaluation of thermal burn patients?}

Thermal burns are a leading cause of morbidity and mortality worldwide $[1,2]$. Thermal burn patients should immediately be assessed for airway and hemodynamic instability with simultaneous evaluation for trauma and toxicologic exposure [2-4]. History should include substances burned (e.g., plastics, associated with cyanide), location (e.g., outdoors or enclosed space), presence of explosion, and associated trauma. Primary evaluation includes assessment of

Brit Long

brit.long@yahoo.com

John Christopher Graybill

john.c.graybill.mil@mail.mil

Hans Rosenberg

hrosenberg@toh.ca

1 Department of Emergency Medicine, Brooke Army Medical Center, 3841 Roger Brooke Dr, Fort Sam Houston, TX 78234, USA

2 Department of Trauma Surgery and Surgical Critical Care, SAUSHEC, Fort Sam Houston, TX, USA

3 Department of Emergency Medicine, University of Ottawa, Ottawa, ON, Canada airway, breathing, circulation, disability, and complete exposure of the patient, with evaluation for respiratory distress and smoke inhalation [2]. Extremity perfusion should be assessed and monitored in circumferential or near circumferential burns. Up to $5 \%$ of thermal burn patients have concomitant traumatic injury $[4,5]$.

Assessment of the thermal burn injury includes burn depth, extent measured by total body surface area (TBSA), and anatomic location (Supplemental Table 1) [2, 3]. Superficial burns are not included in assessment of TBSA (Fig. 1). Clinicians can approximate TBSA in adults using the Lund-Browder chart (the most accurate assessment in children and adults) or Rule of Nines (most expeditious method) (Supplementary Fig. 1) [1-3]. The palm method may also be used, in which the patient's entire palmar surface and fingers is $1 \%$ TBSA [1-3]. This method can be helpful in those with burns $<15 \%$ (15 hands) or $>85 \%$ (number of hands not involved subtracted from $100 \%)$.

\section{What is the optimal fluid resuscitation target and fluid?}

Fluid resuscitation is a critical component of management in those with thermal burns involving $>20 \%$ TBSA in adults ( $10 \%$ in pediatric patients) to increase intravascular volume and end organ perfusion [2, 3]. Two large bore intravenous (IV) lines should be placed, ideally through unburned skin. Under-resuscitation leads to hypoperfusion, while overresuscitation may lead to pulmonary edema and abdominal compartment syndrome [1-3]. Primary markers of resuscitation include vital signs and urine output, titrating fluids to a target of $0.3-0.5 \mathrm{~mL} / \mathrm{kg} / \mathrm{hr}$ for adults $(1.0 \mathrm{~mL} / \mathrm{kg} / \mathrm{hr}$ in children) [2, 3]. Several strategies are available for calculating fluid resuscitation, including the Parkland formula, modified Brooke formula, and Rule of Tens [1-3]. These formulae should only be used as a guide, as various comorbidities affect fluid requirements $[2,3]$. While the Parkland formula 
Fig. 1 Infographic

\section{Just the Facts: Evaluation and Management of Burns}
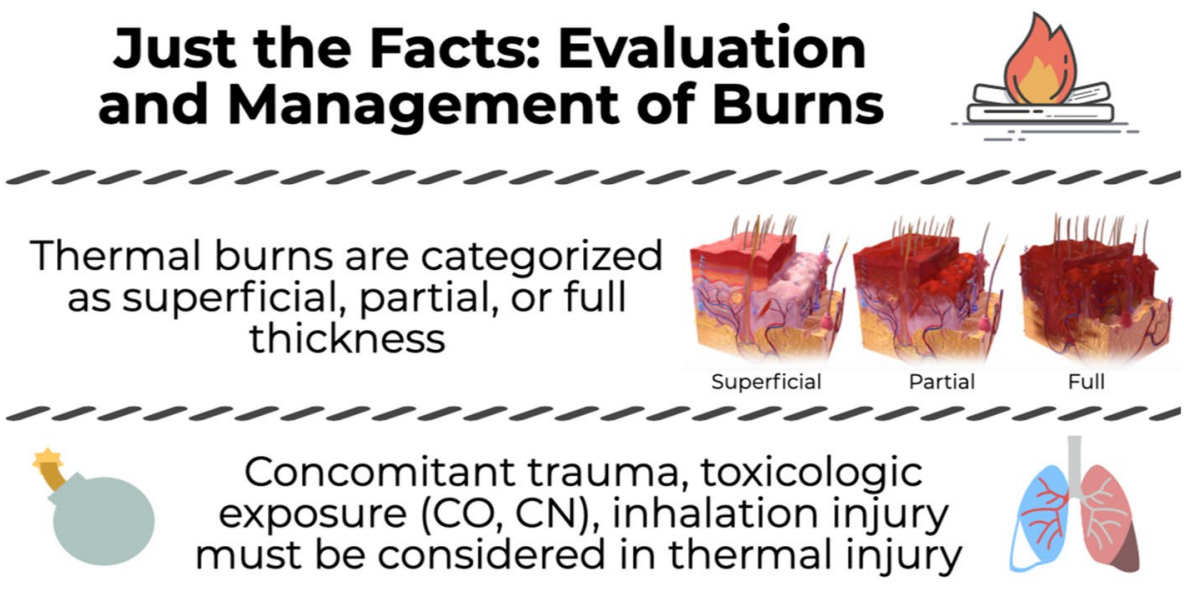

Assessment of TBSA: may use Lund-

Browder Chart (preferred in children), Rule of Nines, Palm Method

Do not include superficial burns in TBSA
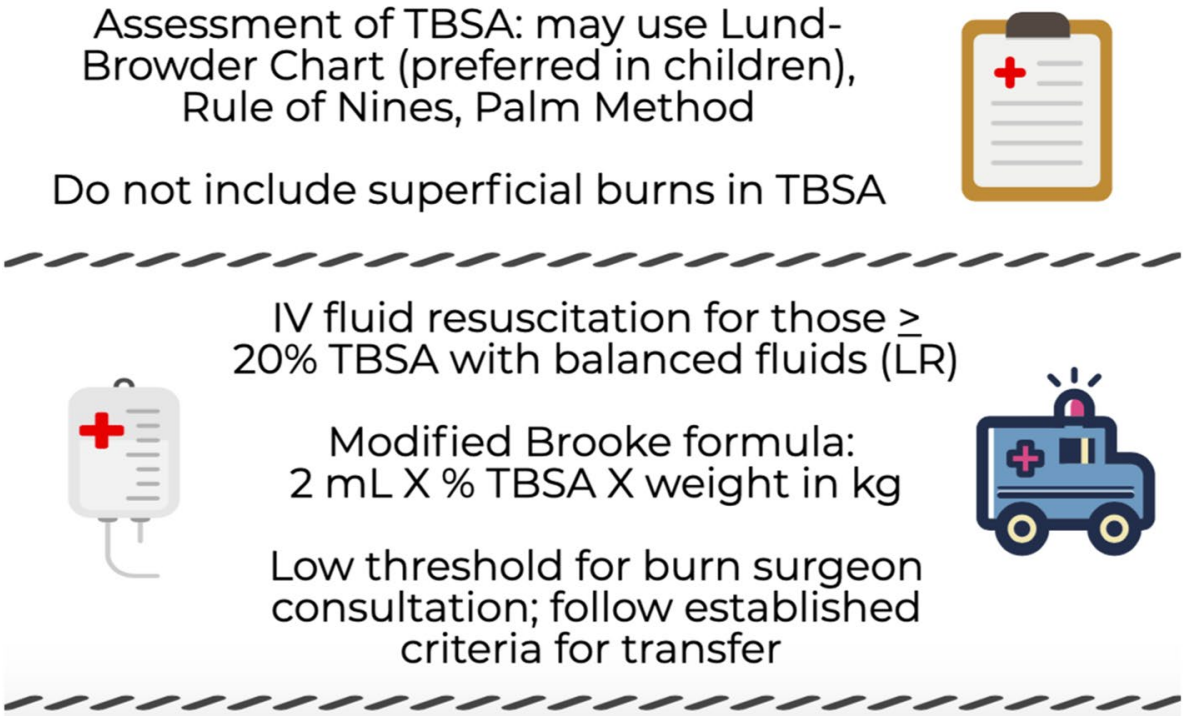

was previously commonly used, this formula is associated with risk of fluid overload [1-3]. Authors of this review recommend the modified Brooke formula, which is $2 \mathrm{~mL} \mathrm{X} \%$ TBSA X weight in kilograms, with the first half given over the first $8 \mathrm{~h}$ from the time of injury and the second half over the following $16 \mathrm{~h}$.

For patients with isolated thermal burn injury, balanced crystalloids are recommended for fluid resuscitation [2]. Colloids, hypertonic saline, and blood product transfusion are not recommended in the initial stages of resuscitation, and should likely be limited to burn centres or critical care settings with expertise in burn resuscitation [2].

\section{How should thermal burn wounds be managed?}

Initial treatment of the thermal burn includes removal of burned clothing, debris, and jewelry [2, 3]. Thermal burn areas should be immediately cooled and gently irrigated with running water, which can minimize the injury zone.
Avoid ice, which can worsen the injury. Tetanus immunization should be updated if needed. For patients requiring rapid transfer, thermal burns should be gently cleansed and covered with a clean, dry sheet [2, 3]. All other patients with thermal burns require wound care and dressing application. Clinicians should follow local practices/preferences regarding burn blister debridement. Ruptured blisters can be removed, but management of clean and intact blisters is controversial [2]. Needle aspiration is not recommended. Large, painful bullae or those over a joint or large crease should be considered for debridement, and unroofing blisters may assist in assessment of thermal burn depth if unclear. Dressings include a nonadherent mesh gauze with a thin layer of topical antibiotics such as bacitracin or mupirocin [2]. Silver sulfadiazine is not recommended, as it has no clear benefit over other antibiotic agents and may have a negative impact on wound healing [2]. Reassessment every $24 \mathrm{~h}$ is recommended, as burns evolve and declare their depth in the first $72 \mathrm{~h}[2,3]$. Consideration of escharotomy in circumferential 
burns should be based on distal neurovascular status, especially in the setting of delays in transfer to a burn centre.

\section{What findings suggest inhalation injury?}

Inhalation injury occurs via three mechanisms: systemic poisoning from inhaled toxins, obstruction of upper airway due to heat injury and edema, or chemical injury to the lower respiratory system due to inhalation of smoke [2,3]. Altered mental status following smoke exposure in an enclosed space suggests possible carbon monoxide or cyanide poisoning, treated with supplemental/hyperbaric oxygen and cyanocobalamin/Cyanokit, respectively. Burns to the buccal cavity, hoarseness, or stridor suggest imminent upper airway obstruction, and definitive airway management should be considered. Soot in the oral airway is a sign of smoke inhalation. Wheeze, cough, and hypoxemia can present up to $48 \mathrm{~h}$ and indicate lower respiratory injury. Bronchoscopy is considered the gold standard for assessment of inhalation injury [2].

\section{Who should be transferred to a burn centre?}

The American Burn Association developed criteria for transfer to a burn centre (Supplemental Table 2) [1, 2]. Burn centre referral should always be guided by clinical judgment, transferring hospital resources, and consultation with the burn centre receiving team.

\section{Case resolution}

The thermal burns appear to be partial thickness, involving 28\% TBSA without evidence of inhalation injury. You gently cleanse and cover the thermal burns with a clean, dry sheet for transfer. The patient's weight is $80 \mathrm{~kg}$, and you calculate he needs $2240 \mathrm{~mL}$ over the first $8 \mathrm{~h}$ based on the modified Brooke formula. Due to the patient's TBSA and involvement of the perineum, transfer to the regional burn centre is arranged.

\section{Key points}

1. Patients with thermal burn injury should be assessed for traumatic injury and toxicologic exposure.

2. Assessment of the thermal burn injury includes burn depth, extent, and anatomic location. TBSA should be assessed using the Lund-Browder Chart, Rule of Nines, or palm method.

3. Fluid resuscitation should be initiated for those with $>$ $20 \%$ TBSA according to the modified Brooke formula and titrated to the patient's clinical condition, vital signs, and urine output.

4. All thermal burn patients should be assessed for inhalation injury.

5. The American Burn Association has established criteria for which burn injuries require transfer to a dedicated burn centre.

Supplementary Information The online version contains supplementary material available at https://doi.org/10.1007/s43678-021-00222-8.

Acknowledgements $\mathrm{BL}, \mathrm{CH}$, and JCG conceived the idea for this manuscript, obtained permission for submission from Dr. Paul Atkinson, and contributed substantially to the writing and editing of the review. This manuscript did not utilize any grants or funding, and it has not been presented in abstract form. This clinical review has not been published, it is not under consideration for publication elsewhere, its publication is approved by all authors and tacitly or explicitly by the responsible authorities where the work was carried out, and that, if accepted, it will not be published elsewhere in the same form, in English or in any other language, including electronically without the written consent of the copyright-holder. This review does not reflect the views or opinions of the U.S. government, Department of Defense, U.S. Army, U.S. Air Force, or SAUSHEC EM Residency Program.

\section{Declarations}

Conflict of interest The authors declare that they have no conflicts of interest.

\section{References}

1. American Burn Association. National Burn Repository 2019 Update, Report of data from 2009-2018. https://ameriburn.siteym.com/store/ViewProduct.aspx?id=14191872 (2019).

2. ISBI Practice Guidelines Committee; Steering Subcommittee; Advisory Subcommittee. ISBI practice guidelines for burn care. Burns. 2016;42(5):953-1021.

3. Hettiaratchy S, Papini R. Initial management of a major burn: II-assessment and resuscitation. BMJ. 2004;329(7457):101-3.

4. Brandt CP, Yowler CJ, Fratianne RB. Burns with multiple trauma. Am Surg. 2002;68(3):240-3 (discussion 243-4).

5. Rosenkranz KM, Sheridan R. Management of the burned trauma patient: balancing conflicting priorities. Burns. 2002;28(7):665-9. 